\title{
A molecular survey of Theileria and Babesia parasites in cattle, with a note on the distribution of ticks in Tunisia
}

\author{
Y. M'ghirbi • A. Hurtado • J. F. Barandika • K. Khlif • \\ Z. Ketata $\cdot$ A. Bouattour
}

(C) Springer-Verlag 2008

Erratum to: Parasitol Res (2008) 103:435-442

DOI 10.1007/s00436-008-0995-3

Unfortunately the name of J.F. Barandika was misspelled in the original publication.

The online version of the original article can be found at http://dx.doi. org/10.1007/s00436-008-0995-3.

Y. M'ghirbi · A. Bouattour $(\bowtie)$

Service d'Entomologie Médicale, Institut Pasteur de Tunis,

1002 Tunis, Tunisia

e-mail: ali.bouattour@pasteur.rns.tn

Y. M'ghirbi

e-mail: youmna_mgh@hotmail.com

A. Hurtado · J. F. Barandika

Department of Production and Animal Health,

NEIKER - Instituto Vasco de Investigación y Desarrollo Agrario,

Berreaga 1,

48160 Derio, Bizkaia, Spain

A. Hurtado

e-mail: ahurtado@neiker.net

K. Khlif $\cdot$ Z. Ketata

Circonscription Santé Animale,

CRDA Zaghouan, Zaghouan, Tunisia 